\title{
LIII. On the motion of floating bodies in running water
}

\section{Peter Barlow Esq.}

To cite this article: Peter Barlow Esq. (1809) LIII. On the motion of floating bodies in running water, Philosophical Magazine Series 1, 33:132, 300-302, DOI: 10.1080/14786440908562871

To link to this article: http://dx.doi.org/10.1080/14786440908562871

曲 Published online: 18 May 2009.

Submit your article to this journal $\pi$

Џ Article views: 4

Q View related articles $\sqsubset$ 


\section{[ 300 ]}

I.III. On the Motion of floating Bodies in running Water. By Peter Karlow, Esq., of the Rayal Military Academy, Woolwich.

To Mr. Tilloch, -Sir,

IN your Magazine for March, I have observed a letter from Mr. G. Orr, wherein he endeavours to account for some partic:lar circumstances in the motion of floating bodies in running waters, that have been noticed by Capt. Burney, and which, it seems, formed the subject of a paper that was read before the Royai Society. In order to accomplish this, Mr. Orr has called in the assistances of the inclined plane, and the doctrine of gravity, or, as be calls them, the laws of matter and motion. Mr. Orr will excuse me, at least $\mathrm{I}$ hope so, when $I$ inform him that he does not seem to comprehend what those laws are. He is not, perhaps, aware that, in the sense that he attaches to them, he is reviving the old exploded notions of Aristotle, which ever since the time of Galileo have been known to be erroneous :-that celebrated philosopher proved that, by the law of gravity, all bodies, whatever their magnitude and density may be, fall through equal spaces in equal times; and when this is not the case, it arises from those laws being counteracted by some other force. Thus in the case given by Mr. Orr, of two globes of equal naagnitudes and different densities rolling down an inclined plane, were they left solely to the action of gravity,for instance, had the experiment been made in vacuo, they would both have descended in the same time; and the reason they do not in ordinary experiments, is because the force of gravity is counteracted by the resistances of the atmosphere; for, both bodies having equal dimensions, they experience equal resistances in their descent, and consequently that body which opposes the greatest force to this resistance, that is, the heaviest body, will descend with the greatest velocity. We see, therefore, that instead of gravity being the cause of the different rates of descent of the two bodies, the circum stance must be attributed to its laws being counteracted. Mr. Orr is not less mistaken in considering this as a parallel case to two bodies floating in running water; 
for in the former case the bodics move through a medium which is perfectly at rest ; and in the latter the medium itself is in motion, and is the cause of the motion of the bodies.

Having thus, I think, satisfactorily shown that Mr. Orr's laws of matter and motion are not sufficient to account for the circumstance alluded to by Capt. Burney, I will venture to offer my own conjectures on this subject;-but this I do with considerable diffidence, and soliciting a correction of any errors that may be discovered therein by any of your ingenious correspondents.

Let us then suppose the case of a bcam of timber loaded at one end; and let us conceive that in the first instance the beam moves parallel to itself, or that the velocitics of the two ends are equal : then it is evident that the heaviest end will acquire the greatest momentum, and consequently, if the beam should experience any resistance in its motion, that end of it which possesses the greatest momentum will oppose that resistance with the greatest effect, and will thus be thrown foremost; and this will continue to be the case, till its direction coincide with that of the stream.

What the resistance is that the beam experiences, and from what cause it arises, are not difficult to determine. In such a river as the Thames, where the experiments were made, and where the tide is constantly ebbing and flowing, every particle of water cannot be supposed to move with equal velocities; small eddies, contrary currents, and various other circumstances will prevent that uniformity, though perhaps they may be imperceptible to the eye of even an attentive observer. This being the case, if the beam should be struck by any particles of water moving in a contrary direction, or should the beam stike any that are at rest, or moving in the same direction as itself, but with a less velocity, any of these circumstances will oppose a resistance to the motion of the beam, which it has been shown will be more effectively overcome by that end of it which has the greatest momentum. And in a similar manner we may account for the motion of the two barges. 
302 Memoir on the Formation of the Phosphoric Ether,

Should these conjectures be thought deserving of a place in your next Number, they are very much at your service.

April 7, 1809.

Yours, \&c.,

Peter Barlow.

LIV. Memoir upon the Formation of the Phosphoric Ether, by Means of a particular Apparatus. By M. Boullay, Chemist, in Paris.-Read to the First Class of the $\mathrm{Na}$ tional Institute the 23d of March, 1807* *

S

$\mathrm{S}_{\text {chence }}$ and Lavoisier had repeatedly tried without success, to transform alcohol into ether, by the action of the phosphoric acid; when at last $M$. Boudet jun., an apothecary of Paris, published a Memoir upon the subject, in tome xl. of the Annales de Chimie. The phænomena which he describes announce a real action between the acid and the alcohol, and manifest several circumstances which generally accompany the process of etherification. According to his own admission, however, the produce he obtained was not very volatile, totally insoluble in water; and al though it had a peculiar smell, it did not present the characters of a true ether.

Convinced by various trials that the want of action of the concentrated or even vitreous phosphoric acid upon alcohol, was particularly owing to the difficulty of uniting these two substances, of multiplying and prolonging the contact of their reciprocal molecules, I resumed the experiments, and the hope I entertained of attaining a more satisfactory result was realized by the following experiment :-

To a tubulated retort placed upon a sandbath, I adjusted a bell-glass also tubulated, which communicated by a Welter's tube of safety with a flask filled with limewater. From this flask issued a second tube which proceeded under a bellglass attached to the hydro-pneumatic apparatus.

I introduced into the retort 500 grammes of pure phosphoric acid, resulting from the combustion of phosphorus

* From Annales de Chimie, tome lxii, p. 192. 